\title{
Pollen Viability and Germination Capacity of Some New Sweet Cherry Cultivars
}

\author{
Monica PAL $^{(*)}$, Viorel MITRE ${ }^{1)}$, Andreea TRIPON ${ }^{11}$, Laura MACAVEI ${ }^{1)}$, Mihai LAZAR ${ }^{11}$ \\ ${ }^{1}$ Department of Fruit growing, University of Agricultural Sciences and Veterinary Medicine, Cluj- \\ Napoca, Romania \\ ${ }^{*}$ Corresponding author, e-mail: pal.monicadiana@gmail.com
}

Bulletin UASVM Horticulture 72(1) / 2015

Print ISSN 1843-5254, Electronic ISSN 1843-5394

Doi:10.15835/buasvmcn-hort:10645

\begin{abstract}
Pollen of 16 new sweet cherry cultivars ('Carmen', 'Katalin', 'Vera,' 'Bigarreau Burlat', 'Starking Hardy Giant', 'Early Red, ' 'Giant Red', 'Lapins,' ‘Canada Giant', 'Earlise', 'Kordia,', 'Karina,', 'Merchant', 'Sylvia', 'Regina', 'Summit') was collected and investigated microscopically in laboratory for viability and germination capacity. Pollen viability was determinated by applying the colorimetric method, and germination capacity by cultivating pollen on solid medium with $1.5 \mathrm{~g}$ agar $+15 \mathrm{~g}$ sucrose $+100 \mathrm{ml}$ distilled water. It was noticed that fertile pollen varied from approximately $32 \%$ to $80 \%$, and the pollen germination percentages after 3 hours of incubation at temperature of $10^{\circ} \mathrm{C}$, varied between $15.53 \%$ and $82.75 \%$. After 24 hours of incubation under the same temperature of $10^{\circ}$ C, germination capacity ranged between $23.07 \%$ and $84.51 \%$. Germination capacity increased with increasing incubation temperature and period, and the highest germination was obtained at the temperature of $20^{\circ} \mathrm{C}$ after 24 hours of incubation, with $90.09 \%$ capacity of germination in case of 'Carmen' cultivar, and the lowest capacity in case of 'Canada Giant' cultivar, with $42.39 \%$ germination capacity.
\end{abstract}

Keywords: Prunul avium L, pollen, sweet cheery, germination, viability.

\section{INTRODUCTION}

Sweet cherry is a fruit-growing tree with a big economic importance, because of the nutritive, commercial and technological characteristics of the fruits (Budan S. and Gradinariu G., 2000). Pollen quality is important because is directly related to crop quantity and quality of the fruits and allows the knowledge of a genotype value as a pollinator in interfertile combination, as well as artificial hybridization (Ardelean, 1994). Pollen germination capacity depends on various conditions, like environmental factors, or nutrition conditions of species and varieties used (Ercisli, 2007).

\section{AIMS AND OBJECTIVES}

The objective of this study was to investigate the pollen viability and germination capacity of some new sweet cheery cultivars, using fresh pollen on the environmental conditions of ClujNapoca city, in 2014.

\section{MATERIALS AND METHODS}

Pollen viability and germination capacity was evaluate for 16 sweet cherry ('Carmen', 'Katalin', 'Vera', 'Bigarreau Burlat', 'Starking Hardy Giant', 'Early Red', 'Giant Red', 'Lapins', 'Canada Giant', 'Earlise', 'Kordia', 'Karina', 'Merchant', 'Sylvia', 'Regina', 'Summit'), grafted on different rootstocks (Gisella 5, Gisella 6 and Mahaleb) and planted in high density plot ( $4 \times 1,5 \mathrm{~m})$, trained as spindle bush, with trellis system and drip fert-irigation provided. Flowers were collected in April, before opening, from 10 trees of each cultivars. Anthers were removed from flowers in Petri dishes with a medium containing 25\% glacial acetic acid and $75 \%$ absolute ethyl alcohol. After fixing 2 hours, pollen viability was determined microscopically at 


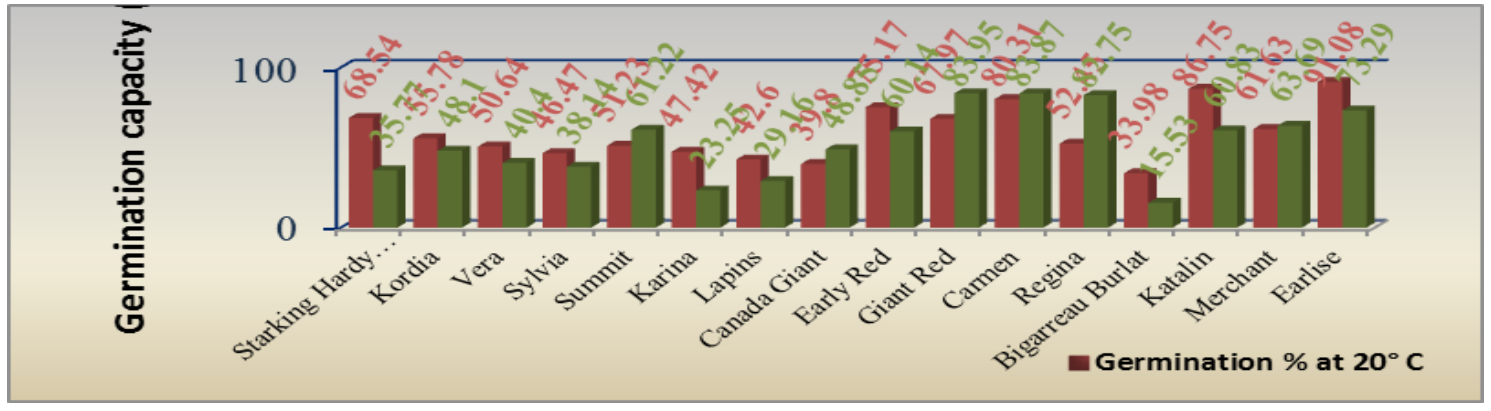

Fig. 1. Pollen germination after 3 hours of incubation at $10^{\circ} \mathrm{C}$ and $20^{\circ} \mathrm{C}$.
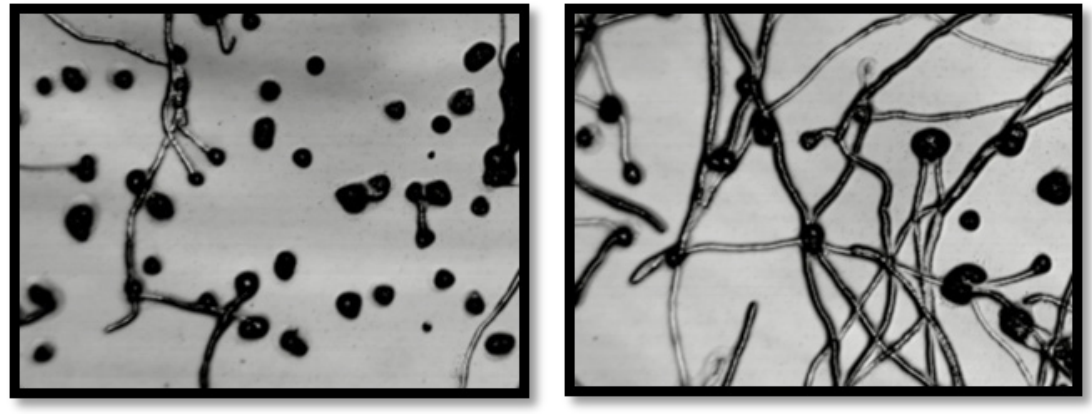

Fig. 2. Pollen germination of sweet cherry cultivars 'Canada Giant' and 'Carmen' after 24 hours of incubation at $20^{\circ} \mathrm{C}$.

40x magnification, using the colorimetric method of staining with iodine with potassium iodide. Pollen germination capacity was determinated by cultivating pollen in Petri dishes on solid medium using $1.5 \mathrm{~g}$ agar $+15 \mathrm{~g}$ sucrose $+100 \mathrm{ml}$ distilled water, under $10^{\circ} \mathrm{C}$ and $20^{\circ} \mathrm{C}$ incubation temperatures.

\section{RESULTS AND DISCUSSION}

Fertile pollen in the presence of the dye, was coloured in carmine red, while sterile pollen remained colourless or slightly coloured. The percent of viability varied from approximately 32 $\%$ in 'Summit' and 'Starking Hardy Giant' cultivars to $80 \%$ in 'Regina' and 'Carmen' case. Cultivars 'Canada Giant', 'Karina', 'Lapins' and 'Early Red' recorded more than $70 \%$ of pollen viability. The pollen germination percentages after 3 hours of incubation at temperature of $10^{\circ} \mathrm{C}$, varied between $15.53 \%$ for 'Bigarreau Burlat' cultivar and 82.75 $\%$ at 'Regina' cultivar. After 24 hours of incubation under the same temperature of $10^{\circ} \mathrm{C}$, germination capacity ranged between $23.07 \%$ in 'Bigarreau Burlat' and $84.51 \%$ in case of 'Carmen' cultivar ( Fig. 1).

Maximum pollen germination exceed at the temperature of $20^{\circ} \mathrm{C}$ after 24 hours of incubation, with $90.09 \%$ capacity of germination in case of 'Carmen' cultivar, and the lowest capacity in case of 'Canada Giant' cultivar, with $42.39 \%$ germination capacity (Fig. 2).

\section{CONCLUSION}

From the results in this work, it can be concluded that temperature affect pollen viability and germination capacity, the highest pollen germination rates were obtained at the temperatured of $20^{\circ} \mathrm{C}$, with $90.09 \%$ capacity of germination in case of 'Carmen' cultivar, and the lowest capacity in case of 'Canada Giant' cultivar, with $42.39 \%$ germination capacity.

\section{REFERENCES}

1. Ardelean, M., (1994), Horticultural plant breeding and experimental technique, Part I, Practical guide, Tipo Agronomia, Cluj-Napoca.

2. Budan S., Grădinariu G., 2000. Cherry tree, Editura Ion Ionescu de la Brad, Iaşi.

3. Ercisli, S. (2007). Determination of pollen viability and in vitro pollen germination of Rosa dumalis and Rosa villosa. Bangladesh Journal of Botany, 36(2), 185-187. 